\title{
Does Give-and-Take Really Matter? Dynamics of Social Interactions in Social Network
}

\author{
Sunghun Chung \\ University of Queensland \\ s.chung@business.uq. \\ edu.au
}

\author{
Animesh Animesh \\ McGill University \\ animesh.animesh@mcg \\ ill.ca
}

\author{
Kunsoo Han \\ McGill University \\ kunsoo.han@mcgill.ca
}

\author{
Alain Pinsonneault \\ McGill University \\ alain.pinsonneault@ \\ $\underline{\text { mcgill.ca }}$
}

\begin{abstract}
Despite the increasing attention paid to the social interaction in online social networks, it is still not clear how social media users interact with each other, consume different content, and expand their social network. This study conceptualizes two types of user engagement (internal and external) and empirically examines the dynamics between user's engagement, friends' engagement, and network size. Using detailed social media activity data collected from over 20,000 Facebook users for three years, we find that when people externally engage in their friends' social space rather than one's own space, they can make more friends and also receive friends' engagement in one's own social space. However, when people receive more friends' engagement in their social space and make more friends, they are likely to reduce their engagement in social media (both externally as well as internally). Our findings can provide useful insights for the literature on social ties, user-generated content, and online peer influence.
\end{abstract}

\section{Introduction}

Are you a social media giver or/and a taker? Scrutinizing this question may be an important component of a social media's revenue model since social media is a tool for connecting individuals and building relationships. People who use social media for personal gain and do not give back to their relationship will see those relationships dwindle whereas those people who spend an extra minute to post helpful information or interesting story will always give something back to their friends, resulting in the large network size. In online social network, a social media user can be either a giver or a taker [35]. From the perspective of social media platforms and firms using social media as a channel to reach its consumers, understanding of peer influence dynamics between social media giver and taker would prove to be advantageous for enhancing the marketing effectiveness. However, the academic literature on social networking has paid relatively less attention to such dynamics between activities of taker versus giver in a social network. Therefore, the main goal of this paper is to investigate such dynamics of social media activities using large-scale data from Facebook.

Facebook is an online medium that allows users to interact with one another (i.e., Friends) by sharing a variety of information and a popular social networking platform that allows registered users to create profile, upload video and photos, send comments and keep in touch with friends. As of March 2016, Facebook is the largest online social network, with 1.09 billion daily active users on average, surpassing other online social networks, such as MySpace and Twitter. Each Facebook profile has a "wall," where either user or his/her friends can post or comments. When two people become friends, they will see updates from their wall through the "news feed" feature. Especially, there are three major activities, namely, posting, commenting, and liking. Wall postings are basically either open to public or limited to user's friends. Users typically post their news or interesting topics with photos and video clips and comment threads to interact with their friends within their own social media space - wall (internally), as well as posting and commenting something in their friends' wall (externally). In this study, we measure and quantify such user-level Facebook activities.

Although recent studies have begun to examine the value of social media $[4,16,26]$, this stream of literature focuses on the relationship between consumers and firms within social media [28, 31], rather than the dynamics between social media users. Recently, Bapna and Umyarov [5] find that peer-topeer influence in online social networks causes increase in buying the service due to the influence coming from users' friends and this effect varies with the network size. However, we have a limited 
understanding of how social media users simultaneously interact with each other, consume different content, and expand their social network. Further, it is not clear what is the interrelationship between such activities and how do these affect the outcome in online social networking. In order to increase and enhance user-generated content contributions for either personal use or business advantage, we expand prior literature by examining the dynamics of social media activities and the interrelationship among network size, a focal user's activities ,and his/her friends' activities. By doing this, we find the factors that lead people to freely share their time and knowledge with others and get some insights of how user's network is formulated. Theoretically, this study focuses on Facebook users' social interaction that indicates non-face-to-face interactions including passive observations and impacts other's expected utility in online social networks [15].

We examine these questions by using a large-scale dataset of individual Facebook activities which contains 492,730 user-week observations from 20,218 users over three years. Utilizing a panel vector autoregression model with exogenous variables (VARX) model, we find a positive temporal effect of user's external engagement (other-oriented activities in friends' social space) on both one's own network size (number of friends) and friends' engagement (activities in one's own social space). However, our results indicate that user's internal engagement (selforiented activities in one's own social space) does not lead to an increase in either network size or friends' engagement. Interestingly, we also find a negative temporal effect of network size and friends' engagement on user's internal and external engagement. By examining the long-term effects, we observe that an increase in user's internal and external engagement only exists for the short period of time (less than three weeks). After three weeks, the influence of network size and friends' engagement on user's internal and external engagement stay in negative. Our findings can provide useful insights for the literature on social ties, user-generated content, and peer influence in online social networks.

\section{Related Literature}

This study is broadly related to extant literature focusing on online social interaction. First, this study relates the process of network formation in online contexts. Katona and Sarvary [21] explore network formation of commercial websites in the presence of search engine and find that the use of search engine strengthens an incentive of websites to specialize in certain content area. In context of Blogs, Mayzlin and Yoganarasimhan [27] find the reason why bloggers choose to link to another blog to increase their audience. Although these studies are helpful to understand the process of network formation in social network, their results are limited to the specific contexts studies in those papers (i.e., WWW, and Blogs).

Second, this study relates to the large literature investigating the influence of user-generated content on online activity. Prior studies examining the effect of user-generated content on economic outcome suggest that user-generated content plays an important role in consumer decisions and the interdependence between creating and purchasing online content [2, 12]. A related stream of literature has also examined the motives of users for generating content and these motives may depend on social media platform. For Wikipedia, Nov [30] found that fun and ideology are the primary drivers of content generation and Zhang and Zhu [38] explain that content generation responds to audience size. In addition, Ross, Orr, Sisic, Arseneault, Simmering and Orr [32] found that a motivation to communicate is the key factor of Facebook use. Although this stream of literature suggests the existence of effects between content generation and social network ties, it does not explicitly investigate the dynamics of network size and users' content generation.

The third stream of research investigates the interplay between user-generated content and social network ties. Network size and structure has influenced in the diffusion of content [22, 37]. Lento, Welser, Gu and Smith [24] test how are the number and nature of social ties related to people's willingness to continue contributing content to a blog, and Shriver, Nair and Hofstetter [34] find that increasing users' social ties on the network induce them to obtain more ties, causing them to post more content. Although these studies provide valuable implications by highlighting the relationship between user-generated content and social network ties, they do not articulate the notion of giver/taker (or users/friends) in social network and do not shed light on the simultaneous and recursive relationship between user-generated content and friend-generated content. Therefore, we extend prior studies by examining the dynamics of user's engagement and their friends' engagement through the perspectives of give and take. Especially, we consider user's engagement as "give" dimension, and user's network size and friends' engagement as "take" dimension which also varies considerably as the outcome of user's engagement.

In online social network, all friendships are indistinguishable in terms of social tie strength, social 
network services such as Facebook are used primarily to maintain or reinforce existing offline relationships rather than to meet new people [14]. Under such weak tie, the user may expect reactions from their friends such as commenting and liking when they post or comment something. Previous literature adopts various concepts of "user activity," which designates the behavioral orientation related to digital content [6, 20]. In this study, we posit that all these activities can be largely categorized either as "self-oriented usages" (e.g., posting on one's own wall) or "other-oriented usages” (e.g., posting on friends' wall) based on its behavioral orientations [13]. In this view, self-oriented activities such as posting selfie on one's own wall can be characterized by one's enjoyment maximization, whereas other-oriented activities such as positively commenting on others' selfie can emphasize principles such as selflessness, cooperation, and concern for the enjoyment of others [10]. For ease of understanding, we treat internal activities within one's own social media space as a self-oriented activity dimension and external activities across friends' social media spaces as an other-oriented activity dimension. Thus, to answer our research questions, we examine the recursive dynamics among network size, user's internal or external engagement, and friends' engagement in online social network and their temporal dynamics. Specifically, by conceptualizing two types of user engagement (internal vs. external) and empirically examining the dynamics among user's engagement, friends' engagement, and network size, we address following questions:

1) Does a user's internal (vs. external) engagement influence friends' following engagement?

2) Does a user's internal (vs. external) engagement influence his/her social network size?

3) Conversely, does friends' engagement influence a user's internal (vs. external) engagement?

4) Does a user's social network size influence his/her internal (vs. external) engagement? and

5) How are these activities temporally proximal to each other? How long does such an effect last, how does it vary across content types?

\section{Data and Empirical Settings}

We mainly use Facebook users' activities data to examine our research questions. Our Facebook data was collected by our custom-designed distributed computing platform, the Apache Hadoop Hive-based crawler. Our data collection was conducted at the end of 2012. ${ }^{1}$ By using thirty Linux x86 servers running in parallel, data-mining agents queried the Facebook servers in order to acquire the specific posts and comment information on each user's Facebook wall. It is important to note that we could only include users who set their privacy settings as "public" (i.e., anyone on or off Facebook) into our sample. Further, we did not analyze contents of posts/comments that might cause privacy or ethical issues, but only used its frequencies. Instead, it is important to note that we could obtain the timestamp of the posts/comments and the anonymized unique user identification numbers.

In this study, we used a snowball sampling method to construct our sample of Facebook users. We first identified initial seed samples from one of well-known multinational company's Facebook official page. Then data-mining agents moved on to each initial seed user's wall and identified another set of users. Given that we focused on a chain-referral sample of Facebook user by not attempting to estimate directly from the sample to the population, our sampling method is along the lines of respondent-driven sampling which is effectively used to avoid bias in traditional snowball sampling [19, 33]. Specifically, we collected all available data through the Facebook graph API (Application Programming Interface) for each user. This procedure was repeated until getting sufficient sample size and reaching the limit of computing power at our disposal. Next, similar to Da, Engelberg and Gao [11], we aggregated the data at the weekly level for each user and constructed a panel dataset containing each user's weekly social media activities and friends' weekly responses. It is pertinent to mention that we do not use daily data because the variation of users' social media activities at the daily level was relatively small (e.g., the average number of posts was 1.27 per day). Our final sample contained 492,730 user-week observations from 20,218 users over the period from January, 2010 to December, 2012, spanning 141 weeks. Our sample users are from diverse countries (Asia 35\%, North America 25\%, Europe 20\%, South America 5\%, and other 15\%) and they have, on average, 323 Facebook friends, speak 22 different languages, and 52.1 percent of them are female.

We focused on two important aspects of users' social media activities: Give activities and Take activities. From the perspective of an user, Take activities comprise both user's network size (i.e., having many friends) and friends' engagement on one's own wall. On the other hand, Give activities consist of user's internal engagement on one's own

\footnotetext{
${ }^{1}$ As of now, Facebook has changed their policy such that private companies/institutions cannot get a public feed API anymore.
} 
wall and external engagement on friends' wall. Network Size was measured by the total number of Facebook friends of a focal user in week $t$. Since Facebook does not provide the weekly trend of friend size (i.e., time information on the number of friends), we used the unique number of friends who have posted, commented, or liked on user's Facebook wall until week $t$ as a proxy for the network size. To capture Friends Engagement, we use two measures of Friends' Facebook activities: the number of postings and the number comments. We then use a weighted average of the number of friends' postings and comments in week $t$ (weighted by their loadings in the underlying principle components). User Internal (External) Engagement was measured as a weighted average of the number of one's own postings and comments on one's (friends') wall in week $t$. Next, we include the average Post and Comment Length of user in week $t$ (unit: bytes) to control for the amount of information. We also control for the Influence Duration of user's posts by including the average time gap between the time a user posts a message and the time the last comment to the message is posted in week $t$ (unit: days). Table 1 summarizes the descriptive statistics of the variables used in our research.

Table1. Descriptive Statistics

\begin{tabular}{|l|c|c|c|}
\hline No. of observation 492,730 & Mean & $\begin{array}{l}\text { Std. } \\
\text { dev. }\end{array}$ & Max \\
\hline NetworkSize $_{i, t}$ & 88.8 & 166.9 & 9,362 \\
\hline FriendsEngagement $_{i, t}$ & 4.6 & 12.1 & 2,467 \\
\hline UserInternalEngagement $_{i, t}$ & 5.7 & 9.4 & 574 \\
\hline UserExternalEngagement $_{i, t}$ & 0.6 & 2.1 & 544.5 \\
\hline InfluenceDuration $_{i, t}$ & 0.6 & 3.4 & 524.6 \\
\hline PostsLength $_{i, t}$ & 53.1 & 55.5 & 3145 \\
\hline CommentsLength $_{i, t}$ & 32.6 & 28.3 & 8,460 \\
\hline
\end{tabular}

\section{Model and Results}

We estimate a panel vector autoregression model with exogenous variables (VARX) model that examines the dynamic interactions among network size, friends' engagement, user internal engagement, and user external engagement to address potential biases such as endogeneity, auto correlation, and reversed causality. The panel structure of the data allows us to control for unobserved individual-specific heterogeneity. Panel VARX has been used by previous studies [e.g., 1, 8, 26] and allows us to examine the dynamic interactions between Give activities and Take activities in social media. To examine the immediate and lagged effects of give activities (User Internal Engagement and User External Engagement) on take activities (Network Size and Friends Engagement) and vice versa, we specify the following baseline model in which each dependent variable is endogenous and is a linear function of its own past values, the past values of all other dependent variables, a set of exogenous variables, and an error term:

$$
\boldsymbol{y}_{i, t}=\left(\begin{array}{c}
\text { NetworkSize }_{i, t} \\
\text { FriendsEngagement }_{i, t} \\
\text { UserINternalEngagement }_{i, t} \\
\text { UserEXternalEngagement }_{i, t}
\end{array}\right)
$$$$
=\sum_{n=1}^{p} \boldsymbol{\Phi}_{\boldsymbol{n}} \cdot\left(\begin{array}{c}
\text { NetworkSize }_{i, t-n} \\
\text { FriendsEngagement }_{i, t-n} \\
\text { UserINternalEngagement }_{i, t-n} \\
\text { UserEXternalEngagement }_{i, t-n}
\end{array}\right)
$$

$+\boldsymbol{\gamma} \cdot\left[\begin{array}{c}\text { InfluenceDuration }_{i, t-1} \\ \text { PostLength }_{i, t-1} \\ \text { CommentsLength }_{i, t-1}\end{array}\right]+\boldsymbol{\theta}_{\boldsymbol{t}}+\boldsymbol{\mu}_{\boldsymbol{t}}+\boldsymbol{\varepsilon}_{\boldsymbol{i}, \boldsymbol{t}}$

where $\mathbf{y}_{i, t}=$ (Network Size $_{i, t}$, Friends Engagement Fit, $_{\text {, }}$ User Internal Engagement ${ }_{i, t}$, User External Engagement $\left._{i, t}\right)^{\prime}$ is a four-element column vector for user $i$ at week $t$; $\boldsymbol{\Phi}^{\prime}$ s are $4 \times 4$ matrices of slope coefficients for endogenous variables; $p$ is the number of lags; $\boldsymbol{\theta}_{t}=\left(\theta_{1, t}, \theta_{2, t}, \theta_{3, t}, \theta_{4, t}\right)^{\prime}$ is a column vector of time dummies; $\boldsymbol{\mu}_{t}=\left(\mu_{1, t}, \mu_{2, t}, \mu_{3, t}, \mu_{4, t}\right)^{\prime}$ is a column vector of unobserved individual effects; and $\boldsymbol{\varepsilon}_{t}=\left(\varepsilon_{1, t}\right.$, $\left.\varepsilon_{2, t}, \varepsilon_{3, t}, \varepsilon_{4, t}\right)^{\prime}$ is a four-element vector of errors (error terms are serially uncorrelated when a sufficient number of lags $p$ is used). In our model, We consider the three control variables, Influence Duration $_{i, t}$, Post Length $_{i, t}$, and Comments Length ${ }_{i, t}$. Since the lagged dependent variables $\mathbf{y}_{i, t-1}, \mathbf{y}_{i, t-2}, \ldots, \mathbf{y}_{i, t-p}$ in Equation (1) are correlated with the average error term $\overline{\boldsymbol{\varepsilon}}_{i}$ in the within-group estimator, the within-group estimator for the fixed effects model will be biased [29]. We thus estimate the proposed panel VARX model using generalized method of moments (GMM) estimator following prior studies $[7,18,36]$.

Table2. Unit Root Tests

\begin{tabular}{|l|c|c|}
\hline Time series & $\begin{array}{c}\text { Levin-Lin-Chu } \\
\text { Test }\end{array}$ & Fisher-type Test \\
\cline { 2 - 3 } & $\begin{array}{c}\text { Adjusted } t \\
(p \text {-value })\end{array}$ & $\begin{array}{c}\text { Inverse logit } t- \\
L^{*}(p \text {-value })\end{array}$ \\
\hline Network Size & -14.23 & -15.67 \\
& $(0.00)$ & $(0.00)$ \\
\hline Friends & -28.81 & -30.63 \\
Engagement & $(0.00)$ & $(0.00)$ \\
\hline User Internal & -19.06 & -20.55 \\
Engagement & $(0.00)$ & $(0.00)$ \\
\hline User External & -37.86 & -41.94 \\
Engagement & $(0.00)$ & $(0.00)$ \\
\hline
\end{tabular}


For stationary tests, we conduct the Fisher-type unit root test [9] as well as the Levin-Lin-Chu test [25] to verify the absence of unit root in our panel data (H0: All panels contain unit root vs. H1: At least one panel is stationary). The test results are shown in Table 2 and all the tests strongly reject the null hypothesis, thereby indicating that there is no unit root and all of the endogenous variables are stationary.

Table 3. Panel VARX Lag Order Selection

\begin{tabular}{|c|c|c|c|}
\hline Lag Order & M-BIC & M-AIC & M-QIC \\
\hline 1 & -346.94 & -5.80 & -51.42 \\
\hline 2 & -257.82 & 75.45 & -15.77 \\
\hline 3 & -222.43 & 189.01 & 52.15 \\
\hline 4 & -154.75 & 248.83 & 66.36 \\
\hline
\end{tabular}

Note: Model selection measures calculated using pvarsoc for firstto fourth-order panel VAR using the first five lags of dependent variables as instruments is shown above.

Next, to choose the optimal lag order in both panel VARX specification and moment condition, we use moment and model selection criteria (MMSC) for GMM models based on Hansen [18])'s $J$-statistic of over-identifying restrictions [3]. Applying MMSC to the GMM estimator, the criteria for selecting lag order is minimizing M-BIC (Bayesian Information Criterion), M-AIC (Akaike's Information Criterion), and M-QIC (Hannan and Quinn Information Criterion). As shown in Table 3, we fit a first-order ( $t$ 1) panel VARX model using GMM estimation since this has the smallest MMSC. We next conduct the panel VAR-Granger causality Wald tests [17].

Table 4. Granger Causality Tests

\begin{tabular}{|l|c|c|c|c|}
\hline Response to & $(1)$ & $(2)$ & $(3)$ & $(4)$ \\
\hline $\begin{array}{l}\text { (1) Network } \\
\text { Size }\end{array}$ & - & 6.99 & 99.48 & 15.97 \\
$(2)$ Friends & 205.02 & - & 22.27 & 1.54 \\
Engagement & $(0.00)$ & & $(0.00)$ & $(0.21)$ \\
\hline (3) User Internal & 2.38 & 0.32 & - & 0.30 \\
Engagement & $(0.12)$ & $(0.56)$ & & $(0.58)$ \\
\hline $\begin{array}{l}\text { (4) User } \\
\text { External }\end{array}$ & 25.75 & 20.32 & 13.85 & - \\
Engagement & $(0.00)$ & $(0.00)$ & $(0.00)$ & \\
\hline
\end{tabular}

Notes. Numbers in cells are $\chi^{2}$ statistics for the Panel VAR-Granger causality Wald test. Numbers in parentheses are $p$-value.

The null hypothesis is that the excluded variable does not Granger-cause Equation variable. Table 4 presents the summary of the results of Granger causality tests. The results suggest that friends' engagement (user's network size) and user's external engagement Granger-cause user's network size (friends' engagement) $(p<0.01)$ while user's internal engagement does not Granger-cause neither user's network size nor friends' engagement $(p>0.10)$.
Interestingly, only user's network size Granger-causes user's external engagement $\left(\chi^{2}=15.97, p<0.01\right)$ whereas all of user's network, friends' engagement, and user's external engagement Granger-cause user's internal engagement.

The estimation results of our panel VARX model in Table 5 show the short-term effects among Takerelated social media activities and Give-related activities. In the Network Size equation, the coefficient estimate on User Internal Engagement at lag 1 is negative (-0.06) but insignificant, indicating that user's network size will not change in the week subsequent to the week when user's internal engagement (activities in one's own social media space) increases. On the contrary, the coefficient estimate on User External Engagement is positively significant (1.28), indicating that network size will increase next week when user external engagement (activities in Friends' social media space) increases. In another Take-related activities, the Friends Engagement equation shows similar patterns. The results about several control variables suggest that influence duration, posts and comments length could increase user's network size, but will not increase friends' engagement. In sum, the results of "take" dimension indicates that user's external engagement in social networks pays off more than user's internal engagement in terms of network size and friends' engagement.

Table 5. Panel VARX Coefficient Estimates

\begin{tabular}{|c|c|c|c|c|}
\hline \multirow{3}{*}{$\begin{array}{l}(N=20,218, T= \\
141) \\
\text { Independent } \\
\text { variable }\end{array}$} & \multicolumn{4}{|c|}{ Dependent variable } \\
\hline & \multicolumn{2}{|c|}{$\begin{array}{c}\text { "Take" } \\
\text { dimension }\end{array}$} & \multicolumn{2}{|c|}{$\begin{array}{c}\text { "Give" } \\
\text { dimension }\end{array}$} \\
\hline & (1) & (2) & (3) & (4) \\
\hline $\begin{array}{l}\text { (1) Network } \\
\text { Size }_{i, t-1}\end{array}$ & $\begin{array}{l}0.99^{* *} \\
(0.01)\end{array}$ & $\begin{array}{l}-0.01^{* *} \\
(0.01)\end{array}$ & $\begin{array}{l}-0.01^{* *} \\
(0.01)\end{array}$ & $\begin{array}{l}-0.01^{* * *} \\
(0.01)\end{array}$ \\
\hline $\begin{array}{l}\text { (2) Friends } \\
\text { Engagement }_{i, t-1}\end{array}$ & $\begin{array}{l}0.57^{* *} \\
(0.04)\end{array}$ & $\begin{array}{l}0.58^{* *} \\
(0.04)\end{array}$ & $\begin{array}{l}-0.08^{* *} \\
(0.02)\end{array}$ & $\begin{array}{c}0.01 \\
(0.01)\end{array}$ \\
\hline $\begin{array}{l}\text { (3) User Internal } \\
\text { Engagement }{ }_{i, t-1}\end{array}$ & $\begin{array}{l}-0.06 \\
(0.04)\end{array}$ & $\begin{array}{l}-0.02 \\
(0.03)\end{array}$ & $\begin{array}{l}0.60^{* *} \\
(0.02)\end{array}$ & $\begin{array}{l}-0.01 \\
(0.01)\end{array}$ \\
\hline $\begin{array}{l}\text { (4) User External } \\
\text { Engagement }{ }_{i, t-1}\end{array}$ & $\begin{array}{l}1.28^{* *} \\
(0.25)\end{array}$ & $\begin{array}{l}0.82^{* *} \\
(0.18)\end{array}$ & $\begin{array}{l}0.18^{* *} \\
(0.05)\end{array}$ & $\begin{array}{l}0.45^{* *} \\
(0.03)\end{array}$ \\
\hline $\begin{array}{l}\text { Influence } \\
\text { Duration }_{i, t-1}\end{array}$ & $\begin{array}{l}0.06^{* *} \\
(0.01)\end{array}$ & $\begin{array}{c}0.01 \\
(0.01)\end{array}$ & $\begin{array}{l}-0.03^{* *} \\
(0.01)\end{array}$ & $\begin{array}{l}-0.01^{* *} \\
(0.01)\end{array}$ \\
\hline Posts Length ${ }_{i, t-1}$ & $\begin{array}{l}0.01^{* *} \\
(0.01)\end{array}$ & $\begin{array}{c}0.01 \\
(0.01)\end{array}$ & $\begin{array}{c}0.01 \\
(0.01)\end{array}$ & $\begin{array}{c}0.01 \\
(0.01)\end{array}$ \\
\hline $\begin{array}{l}\text { Comments } \\
\text { Length }_{i, t-1}\end{array}$ & $\begin{array}{l}0.02^{* *} \\
(0.01)\end{array}$ & $\begin{array}{c}0.01 \\
(0.01)\end{array}$ & $\begin{array}{l}0.01^{* *} \\
(0.01)\end{array}$ & $\begin{array}{l}-0.01 \\
(0.01)\end{array}$ \\
\hline
\end{tabular}

Meanwhile, in the User INternal (EXternal) Engagement equation which relates to "give" dimension, the coefficient estimates on Network Size at lag 1 are negatively significant $(-0.01$ and -0.01 , respectively) and the coefficient estimates on Friends 
Engagement at lag 1 are negative (-0.08 and -0.01, respectively). These results indicate that user's internal engagement will decrease in the week subsequent to the week when network size and friend's engagement (on one's own social space) increase. In another Give-related activities, the User External Engagement equation shows similar patterns except the insignificant coefficient estimate on friends' engagement. Thus, in general, we find that the short-term effects of Take-related social media activities (i.e., network size, and friends' engagement) on Give-related social media activities (i.e., user's internal and external engagement) are negative.

The different results between Give and Take social media activities is an important findings of this study and suggest that when people engage in their friends' social space rather than one's own space, they can make more friends and receive friends' engagement in one's own social space. However, when people receive more friends' engagement in their social space and make more friends, they are likely to reduce their engagement in social media - both externally as well as internally, resulting a behavioral asymmetry in social network. Although the interpretation of the coefficient estimates on one-period lagged dependent variables would allow us to assess the short-term behavior of the panel VAR model, we should examine the long-term behavior among Take-related and Giverelated social media activities to better understand the dynamics of social interactions.

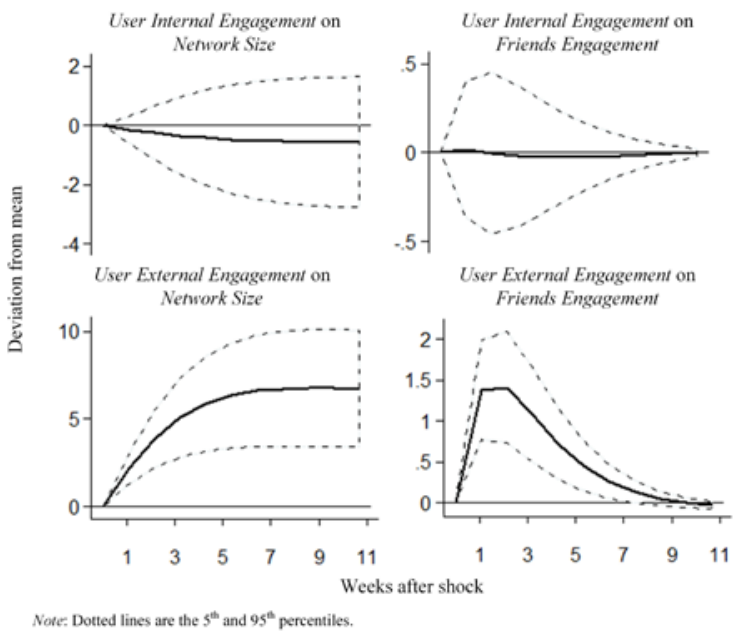

\section{Figure 1. Impulse Response Functions (Give $\rightarrow$ Take)}

To examine the long-term effects of the change in dependent variables, impulse response functions (IRFs) are often used to describe the effect of one unit increase in one variable on the future values of all variables in the system [e.g., 1, 8]. By examining IRFs, we could capture whether a shock to one activity will have a permanent or transitory effect on any other activities and how long transitory effect will take to dissipate. Figure 1 and 2 presents the impulse response functions (IRFs) along with the 90\% confidence intervals generated from 10,000 Monte Carlo simulations draws. We are particularly interested in how network size and friends engagement respond to a shock to user's internal (vs. external) engagement (Figure 1(a-d)) and how user's internal (vs. external) engagement respond to a shock to network size and friends engagement (Figure 2(a-d)) as time goes on.

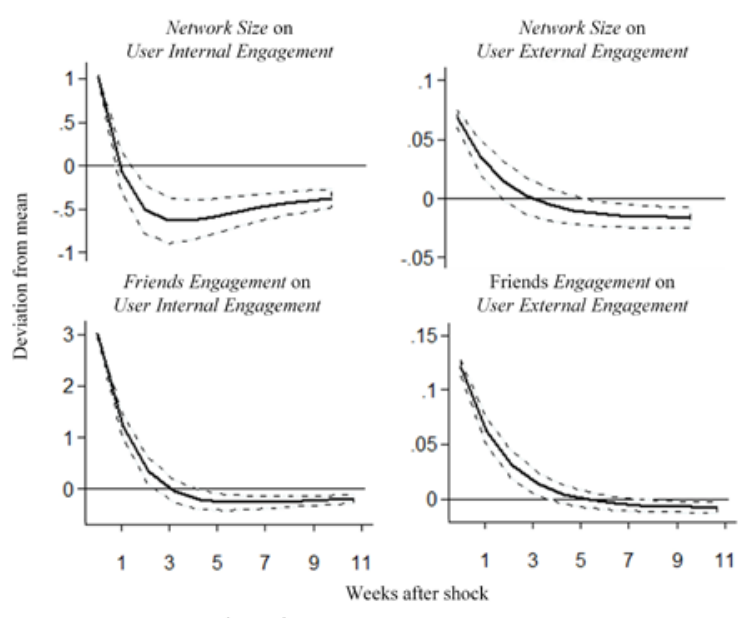

Note: Dotted lines are the $5^{\text {th }}$ and $95^{\mathrm{A}}$ percentiles.

Figure 2. Impulse Response Functions
(Take $\rightarrow$ Give)

Similar to the results from panel VARX model, Figure 1(a) and 1(b) illustrate that the effects of user's internal engagement on both user's network size and friends' engagement are not significantly different from zero. Figure 1(c) and 2(d) illustrate that the effects of user's external engagement on network size and friends' engagement are significantly positive going from week 1 to week 9, but friends' engagement gradually reduce to zero. These results indicate that the effect of user's external engagement on network size is a permanent, whereas friends' engagement respond to a shock to user's external engagement is positively salient in week 2-3 and gradually decrease afterward. In Figure 2, we observe an increase in user's internal and external engagement by network size (Figure 2(a) and 2(b)) and friends' engagement (Figure 2(c) and 2(d)) going from only week 1 to week 3, but most of effects gradually decrease and are significantly different from zero (i.e., negative) from week 3 or 5. These results indicate that Give-activities respond to a shock to Take-activities is positive only for a short 
period of time (i.e., less than 3 weeks) then remain negative afterward. Thus, IRFs provide additional insights of how the system evolves over time, corroborating our main results in Table 5.

\section{Empirical Extensions}

Table 6. Different Contents Variations

\begin{tabular}{|c|c|c|c|c|}
\hline & \multicolumn{4}{|c|}{$\begin{array}{l}\text { Dependent variable } \\
\text { ("Take" dimension") }\end{array}$} \\
\hline $\begin{array}{l}\text { Independent } \\
\text { variable }\end{array}$ & (1) & (2 & & (3) \\
\hline $\begin{array}{l}\text { (1) Network } \\
\text { Size }_{i, t-1}\end{array}$ & $\begin{array}{l}0.98^{* *} \\
(0.01)\end{array}$ & $\begin{array}{l}0.0 \\
(0 . \\
\end{array}$ & & $\begin{array}{l}-0.01^{* *} \\
(0.01) \\
\end{array}$ \\
\hline $\begin{array}{l}\text { (2)Friends } \\
\text { Engagement } i, t \\
\text { on video/photo }\end{array}$ & $\begin{array}{l}-0.10 \\
(0.07)\end{array}$ & $\begin{array}{l}0.2 \\
(0 .\end{array}$ & & $\begin{array}{l}0.02^{* *} \\
(0.01)\end{array}$ \\
\hline $\begin{array}{l}\text { (3) Friends } \\
\text { Engagement }_{i, t} \\
\text { on status/link }\end{array}$ & $\begin{array}{l}0.13^{*} \\
(0.06)\end{array}$ & $\begin{array}{l}0.0 \\
(0 .\end{array}$ & & $\begin{array}{l}0.21^{* *} \\
(0.02)\end{array}$ \\
\hline $\begin{array}{l}\text { User Internal } \\
\text { Engagement } i, t \\
\text { on video/photo }\end{array}$ & $\begin{array}{l}-0.17 \\
(0.12)\end{array}$ & $\begin{array}{l}0.2 \\
(0 .\end{array}$ & & $\begin{array}{c}0.01 \\
(0.01)\end{array}$ \\
\hline $\begin{array}{l}\text { User Internal } \\
\text { Engagement }_{i, t} \\
\text { on status/link }\end{array}$ & $\begin{array}{l}0.38^{* *} \\
(0.06)\end{array}$ & $\begin{array}{l}-0.0 \\
(0 .\end{array}$ & & $\begin{array}{l}-0.07^{* *} \\
(0.02)\end{array}$ \\
\hline $\begin{array}{l}\text { User External } \\
\text { Engagement } i, t \\
\text { on video/photo }\end{array}$ & $\begin{array}{l}12.37^{* *} \\
(3.13)\end{array}$ & $\begin{array}{l}-.5 \\
(0.5\end{array}$ & & $\begin{array}{l}-1.44^{* *} \\
(0.31)\end{array}$ \\
\hline \multirow[t]{2}{*}{$\begin{array}{l}\text { User External } \\
\text { Engagement }_{i, t} \\
\text { on status/link } \\
\end{array}$} & $\begin{array}{l}-2.99^{* *} \\
(0.41)\end{array}$ & $\begin{array}{l}0.2 \\
(0 .\end{array}$ & & $\begin{array}{l}0.82^{* *} \\
(0.09)\end{array}$ \\
\hline & \multicolumn{4}{|c|}{$\begin{array}{l}\text { Dependent variable } \\
\text { ("Give" dimension") }\end{array}$} \\
\hline $\begin{array}{c}\text { Independent } \\
\text { variable }\end{array}$ & (4) & (5) & (6) & (7) \\
\hline Network Size $_{i, t-1}$ & $\begin{array}{l}-0.01^{*} \\
(0.01)\end{array}$ & $\begin{array}{l}-0.01^{* *} \\
(0.01)\end{array}$ & $\begin{array}{l}0.01^{* *} \\
(0.01)\end{array}$ & $\begin{array}{l}-0.01^{* *+} \\
(0.01)\end{array}$ \\
\hline $\begin{array}{l}\text { Friends } \\
\text { Engagement } i, t \\
\text { on video/photo }\end{array}$ & $\begin{array}{l}-0.02 \\
(0.06)\end{array}$ & $\begin{array}{c}0.01 \\
(0.01)\end{array}$ & $\begin{array}{l}-0.01^{*} \\
(0.01)\end{array}$ & $\begin{array}{l}-0.01 \\
(0.01)\end{array}$ \\
\hline $\begin{array}{l}\text { Friends } \\
\text { Engagement }_{i, t} \\
\text { on status/link }\end{array}$ & $\begin{array}{c}0.01 \\
(0.01)\end{array}$ & $\begin{array}{c}0.01 \\
(0.01)\end{array}$ & $\begin{array}{c}0.01 \\
(0.01)\end{array}$ & $\begin{array}{c}0.01 \\
(0.01)\end{array}$ \\
\hline $\begin{array}{l}\text { (4) UserInternal } \\
\text { Engagement } i, t \\
\text { on video/photo }\end{array}$ & $\begin{array}{l}0.64^{* *} \\
(0.06)\end{array}$ & $\begin{array}{l}-0.01 \\
(0.01)\end{array}$ & $\begin{array}{l}0.01^{* *} \\
(0.01)\end{array}$ & $\begin{array}{l}0.01^{* *} \\
(0.01)\end{array}$ \\
\hline $\begin{array}{l}\text { (5) UserInternal } \\
\text { Engagement }_{i, t} \\
\text { on status/link }^{\text {on }}\end{array}$ & $\begin{array}{l}-0.02^{* *} \\
(0.01)\end{array}$ & $\begin{array}{l}0.14^{* *} \\
(0.01)\end{array}$ & $\begin{array}{c}0.01 \\
(0.01)\end{array}$ & $\begin{array}{l}0.01^{* *} \\
(0.01)\end{array}$ \\
\hline $\begin{array}{l}\text { (6)UserExternal } \\
\text { Engagement }_{i, t} \\
\text { on video/photo }\end{array}$ & $\begin{array}{l}-0.13^{* *} \\
(0.05)\end{array}$ & $\begin{array}{l}-0.94^{* *} \\
(0.17)\end{array}$ & $\begin{array}{l}0.31^{* *} \\
(0.03)\end{array}$ & $\begin{array}{l}-0.01 \\
(0.02)\end{array}$ \\
\hline $\begin{array}{l}\text { (7)UserExternal } \\
\text { Engagement }_{i, t} \\
\text { on status/link }^{\text {on }}\end{array}$ & $\begin{array}{l}0.09^{* *} \\
(0.02)\end{array}$ & $\begin{array}{l}0.72^{* *} \\
(0.07)\end{array}$ & $\begin{array}{c}0.01 \\
(0.01)\end{array}$ & $\begin{array}{l}0.44^{* *} \\
(0.02)\end{array}$ \\
\hline
\end{tabular}

One might be concerned about the cross-content type variation in our analysis since each social media content has different amount of information. Given that social media content has both enriched postings (e.g., videos and photos) and text-based postings (e.g., status and links), we divided each Facebook activity by the types of content to get additional insights. Table 6 shows intricate dynamics of different variables. In general, our main results in Table 5 indicate that user's external engagement increases user's network size.

As extending this finding, Table 6 indicates that user's external engagement using enriched contents (video/photo) is more beneficial than using text-based contents (status/link) to increase network size (12.37 vs. $-2.99, p<.01$ ), whereas user's external engagement using status and link is more beneficial than enriched content to increase both friend's engagement on video/photo $(0.23, p<0.01)$ and status/link $(0.82, p<$ $0.01)$. Further, although our main results suggest that user's internal engagement is associated with neither user's network size nor friends' engagement, Table 6 indicates that user's internal engagement focusing on text-based content (status/link) is effective to increase network size $(0.38, p<0.01)$, but ineffective to increase friends' engagement $(-0.04$ and $-0.07, p<$ 0.01 ). In addition, the influence of network size and friends' engagement on users' internal and external engagement across content types are similar to our main results. Applying these findings to business context such as Facebook business pages, we could learn that firms need to focus on text-based contents which might contain more descriptive information in their social media space, while keeping external engagement by using enriched contents to increase firms' network size that might be related to the number of potential customers.

\section{Conclusion and Discussion}

Although we used to interact with a small number of people every day, and a large number of people on an irregular basis, today, we can interact with hundreds of people every day through social media channels and it has already changed how we communicate. Examining the ways in which social media users interact with their friends and associates is helpful to build effective strategies for the commercialization of social spaces. Using large-scale Facebook users' activities data, we employ a panel VARX model utilizes time series data and accounts for the dynamic relationships among user's internal/external engagement, friends' engagement, and user's network size. We find that there is a significant positive effect of user's external 
engagement on both user's network size and friends' engagement, but recursive effects of user's network size and friends' engagement on user's internal and external engagement are only positive for the shortterm period.

This study makes several important contributions to the literature. We conceptualize and quantify users' social media activities which have dynamics each other - friends' engagement, user's internal and external engagement, and network size. Although considerable research has been conducted on the social media, there has been little empirical research regarding the dynamics of network size and user engagement so that the mechanism of how users formulate their social network has been unclear. By having "give-and-take” perspective, and employing a large-scale dataset of individual Facebook activities, this study validates the conjecture that give-and-take is underlying mechanism in online social interaction. Interestingly, we find that when people engage in their friends' social space rather than one's own space, they can make more friends and receive friends' engagement in one's own social space (i.e., give something to friends, then take a benefit from them). However, after people receive more friends' engagement in their social space and make more friends, they are likely to engage into social media neither externally nor internally (i.e., take something from friends, then nothing to give back to them). This chicken or the egg causality could provide an insight to understand social ties and user-generated content [34], peer influence [5], and network formation in online social networks [27]. Our study provides valuable insights to firms about how to formulate their social media strategies by understanding dynamics of social interactions among users.

This study has several limitations and offers directions for the future research. First, although we employed a large-scale dataset of Facebook users by using respondent-driven sampling, our sample only covered $0.002 \%$ of total population of Facebook users, remaining generalization issue. Therefore, replications of this study are needed to enhance the generalizability of the results. Second, we did not study the effects of many different types of content (e.g., informative vs. interesting), but only examine one of the dimensions on which content can be categorized (e.g., photos, or status). As shown in Table 6, it would be interesting to examine whether and how user's engagement on different types of content influence friends' engagement, and vice versa. Finally, results call for future research to develop theoretical model to explain why network size and friends' engagement have a negative influence on user's engagement, which would also extend the new perspective on the undesirable impact of social media on users' subjective well-being [23].

\section{References}

[1] Adomavicius, G., Bockstedt, J., and Gupta, A., "Modeling Supply-Side Dynamics of It Components, Products, and Infrastructure: An Empirical Analysis Using Vector Autoregression", Information Systems Research, 23(2), 2012, pp. 397-417.

[2] Albuquerque, P., Pavlidis, P., Chatow, U., Chen, K.-Y., and Jamal, Z., "Evaluating Promotional Activities in an Online Two-Sided Market of User-Generated Content", Marketing Science, 31(3), 2012, pp. 406-432.

[3] Andrews, D.W.K., and Lu, B., "Consistent Model and Moment Selection Procedures for Gmm Estimation with Application to Dynamic Panel Data Models", Journal of Econometrics, 101(1), 2001, pp. 123-164.

[4] Aral, S., Dellarocas, C., and Godes, D., "Social Media and Business Transformation: A Framework for Research", Information Systems Research, 24(1), 2013, pp. 3-13.

[5] Bapna, R., and Umyarov, A., "Do Your Online Friends Make You Pay? A Randomized Field Experiment on Peer Influence in Online Social Networks", Management Science, 61(8), 2015, pp. 1902-1920.

[6] Bhattacharjee, S., Gopal, R.D., Lertwachara, K., Marsden, J.R., and Telang, R., "The Effect of Digital Sharing Technologies on Music Markets: A Survival Analysis of Albums on Ranking Charts", Management Science, 53(9), 2007, pp. 1359-1374.

[7] Binder, M., Hsiao, C., and Pesaran, M.H., "Estimation and Inference in Short Panel Vector Autoregressions with Unit Roots and Cointegration", Econometric Theory, 21(4), 2005, pp. 795-837.

[8] Chen, H., De, P., and Hu, Y.J., "It-Enabled Broadcasting in Social Media: An Empirical Study of Artists' Activities and Music Sales", Information Systems Research, 26(3), 2015, pp. 513-531.

[9] Choi, I., "Unit Root Tests for Panel Data", Journal of International Money and Finance, 20(2), 2001, pp. 249272.

[10] Cropanzano, R., Goldman, B., and Folger, R., "SelfInterest: Defining and Understanding a Human Motive", Journal of Organizational Behavior, 26(8), 2005, pp. 985-991.

[11] Da, Z., Engelberg, J., and Gao, P., "In Search of Attention", Journal of Finance, 66(5), 2011, pp. 14611499.

[12] Dellarocas, C., "Strategic Manipulation of Internet Opinion Forums: Implications for Consumers and Firms", Management Science, 52(10), 2006, pp. 15771593.

[13] Dreu, C.K.W.D., and Nauta, A., "Self-Interest and Other-Orientation in Organizational Behavior: Implications for Job Performance, Prosocial Behavior, and Personal Initiative", Journal of Applied Psychology, 94(4), 2009, pp. 913-926.

[14] Ellison, N.B., Steinfield, C., and Lampe, C., "The Benefits of Facebook "Friends:" Social Capital and 
College Students' Use of Online Social Network Sites", Journal of Computer-Mediated Communication, 12(4), 2007, pp. 1143-1168.

[15] Godes, D., Mayzlin, D., Chen, Y., Das, S., Dellarocas, C., Pfeiffer, B., Libai, B., Sen, S., Shi, M., and Verlegh, P., "The Firm's Management of Social Interactions", Marketing Letters, 16(3), 2005, pp. 415-428.

[16] Goh, K.-Y., Heng, C.-S., and Lin, Z., "Social Media Brand Community and Consumer Behavior: Quantifying the Relative Impact of User- and MarketerGenerated Content", Information Systems Research, 24(1), 2013, pp. 88-107.

[17] Granger, C.W.J., "Investigating Causal Relations by Econometric Models and Cross-Spectral Methods", Econometrica, 37(3), 1969, pp. 424-438.

[18] Hansen, L.P., "Large Sample Properties of Generalized Method of Mements Estimators", Econometrica, 50(4), 1982, pp. 1029-1054.

[19] Heckathorn, D.D., "Respondent-Driven Sampling: A New Approach to the Study of Hidden Populations", Social Problems, 44(2), 1997, pp. 174-199.

[20] Johar, M., Menon, S., and Mookerjee, V., "Analyzing Sharing in Peer-to-Peer Networks under Various Congestion Measures", Information Systems Research, 22(2), 2011, pp. 325-345.

[21] Katona, Z., and Sarvary, M., "Network Formation and the Structure of the Commercial World Wide Web", Marketing Science, 27(5), 2008, pp. 764-778.

[22] Katona, Z., Zubcsek, P.P., and Sarvary, M., "Network Effects and Personal Influences: The Diffusion of an Online Social Network", Journal of Marketing Research, 48(3), 2011, pp. 425-443.

[23] Krasnova, H., Widjaja, T., Buxmann, P., Wenninger, H., and Benbasat, I., "Why Following Friends Can Hurt You: An Exploratory Investigation of the Effects of Envy on Social Networking Sites among College-Age Users", Information Systems Research, 26(3), 2015, pp. 585-605.

[24] Lento, T., Welser, H.T., Gu, L., and Smith, M., "The Ties That Blog: Examining the Relationship between Social Ties and Continued Participation in the Wallop Weblogging System", in: Book The Ties That Blog: Examining the Relationship between Social Ties and Continued Participation in the Wallop Weblogging System, Edinburgh, Scotland, 2006

[25] Levin, A., Lin, C.-F., and Chu, C.-S.J., "Unit Root Tests in Panel Data: Asymptotic and Finite-Sample Properties", Journal of Econometrics, 108(1), 2002, pp. 2002.

[26] Luo, X., Zhang, J., and Duan, W., "Social Media and Firm Equity Value", Information Systems Research, 24(1), 2013, pp. 146-163.

[27] Mayzlin, D., and Yoganarasimhan, H., "Link to Success: How Bologs Build an Audience by Promoting Rivals", Management Science, 58(9), 2012, pp. 16511668.

[28] Miller, A.R., and Tucker, C., "Active Social Media Management: The Case of Health Care", Information Systems Research, 24(1), 2013, pp. 52-70.

[29] Nickell, S., "Biases in Dynamic Models with Fixed Effects", Econometrica, 49(6), 1981, pp. 1417-1426.
[30] Nov, O., "What Motivates Wikipedians?", Communication of ACM, 50(11), 2007, pp. 60-64.

[31] Rishika, R., Kumar, A., Janakiraman, R., and Bezawada, R., "The Effect of Customers' Social Media Participation on Customer Visit Frequency and Profitability: An Empirical Investigation", Information Systems Research, 24(1), 2013, pp. 108-127.

[32] Ross, C., Orr, E.S., Sisic, M., Arseneault, J.M., Simmering, M.G., and Orr, R.R., "Personality and Motivations Associated with Facebook Use", Computers in Human Behavior, 25(2), 2009, pp. 578586.

[33] Salganik, M.J., and Heckathorn, D.D., "Sampling and Estimation in Hidden Populations Using RespondentDriven Sampling", Sociological Methodology, 34(2004, pp. 193-239.

[34] Shriver, S.K., Nair, H.S., and Hofstetter, R., "Social Ties and User-Generated Content: Evidence from an Online Social Network", Management Science, 59(6), 2013, pp. 1425-1443.

[35] Summers, S., "Are You a Social Media Giver or a Taker?", in: Book Are You a Social Media Giver or a Taker?, 2014

[36] Tirunillai, S., and Tellis, G.J., "Does Chatter Really Matter? Dynamics of User-Generated Content and Stock Performance", Marketing Science, 31(2), 2012, pp. 198215.

[37] Yoganarasimhan, H., "Impact of Social Network Structure on Content Propagation: A Study Using Youtube Data", Quantitative Marketing and Economics, 10(1), 2012, pp. 111-150.

[38] Zhang, X.M., and Zhu, F., "Group Size and Incentives to Contribute: A Natural Experiment at Chinese Wikipedia", American Economic Review, 101(4), 2011, pp. 1601-1615. 